\title{
Assessment of Workers Knowledge toward Healthy workplace Hazards at Kirkuk Carpet Factory
}

\author{
Marghoob Hussien Yaas*
}

\begin{abstract}
Background and aim: With an ever-increasing demand for a comfortable living in recent days, the number of industries like carpet and textile industries is on the increase. The increasing of this industry also brings an occupational hazards like dust and chemical hazards that effect on worker health as well as their family. The study aimed to assess the workers' knowledge toward healthy workplace hazards at the Kirkuk Carpet Factory.

Materials and method: A descriptive (non-experimental) design was carried out through the period from $25^{\text {th }}$ December 2016 through $15^{\text {th }}$ May 2017 in order to assess the Workers Knowledge toward Healthy workplace Hazards at Kirkuk Carpet Factory.

A purposive (non-probability) sample is selected for the study, which includes (60) workers worked in the Kirkuk Carpet Factory. Assessment questionnaire consists of three parts that includes demographic characteristic; Dusts hazards and Chemical material Hazards domains, and the Data were gathered through the worker interviewed in the workplace. Data were analyzed through the application of descriptive statistical (frequencies and percentages) and inferential statistical (mean of score with $\mathrm{SD} \pm$ ).

Results: The Overall results showed that most workforces were married women with low educational level and they have a significant knowledge and awareness of the workplace health hazards that related to dusts and chemical materials hazards that may be arise from the workers' workplace.

Conclusion: The healthy wellness for workers of carpet factory reveals their knowledge of the work hazards such as dust and chemical hazards in the workplace by taking all protective measures and equipment's that protect them from those hazards in order to maintain their health status.

Recommendations: A health educational programs and training should provide for all workers with regularly and periodically also collaboration and organization must be done between all related Ministries in order to prevent the hazards affected workers and workplace environment.

Keywords: Carpet, Hazards, Knowledge, Workers.
\end{abstract}

* Lecturer / College of Nursing / University of Tikrit 